\title{
The incidence of Cushing's disease: a nationwide Swedish study
}

\author{
Oskar Ragnarsson ${ }^{1}$ (D) - Daniel S. Olsson ${ }^{1} \cdot$ Dimitrios Chantzichristos $^{1} \cdot$ Eleni Papakokkinou ${ }^{1} \cdot$ Per Dahlqvist $^{2}$. \\ Elin Segerstedt ${ }^{2} \cdot$ Tommy Olsson $^{2} \cdot$ Maria Petersson $^{3,4} \cdot$ Katarina Berinder $^{3,4} \cdot$ Sophie Bensing ${ }^{3,4}$. \\ Charlotte Höybye ${ }^{3,4}$. Britt Edén Engström ${ }^{5}$. Pia Burman ${ }^{6,7} \cdot$ Lorenza Bonelli,7 $^{6,7}$ Cecilia Follin $^{8}$. David Petranek ${ }^{8}$. \\ Eva Marie Erfurth ${ }^{8}$. Jeanette Wahlberg ${ }^{9} \cdot$ Bertil Ekman $^{9} \cdot$ Anna-Karin Åkerman $^{10} \cdot$ Erik Schwarcz $^{10}$. \\ Ing-Liss Bryngelsson ${ }^{11} \cdot$ Gudmundur Johannsson ${ }^{1}$
}

Published online: 25 February 2019

(C) The Author(s) 2019

\begin{abstract}
Background Studies on the incidence of Cushing's disease (CD) are few and usually limited by a small number of patients. The aim of this study was to assess the annual incidence in a nationwide cohort of patients with presumed CD in Sweden. Methods Patients registered with a diagnostic code for Cushing's syndrome (CS) or CD, between 1987 and 2013 were identified in the Swedish National Patient Registry. The CD diagnosis was validated by reviewing clinical, biochemical, imaging, and histopathological data.

Results Of 1317 patients identified, 534 (41\%) had confirmed CD. One-hundred-and-fifty-six (12\%) patients had other forms of CS, 41 (3\%) had probable but unconfirmed CD, and 334 (25\%) had diagnoses unrelated to CS. The mean (95\% confidence interval) annual incidence between 1987 and 2013 of confirmed CD was 1.6 (1.4-1.8) cases per million. 1987-1995, 1996-2004, and 2005-2013, the mean annual incidence was $1.5(1.1-1.8), 1.4(1.0-1.7)$ and $2.0(1.7-2.3)$ cases per million, respectively. During the last time period the incidence was higher than during the first and second time periods $(P<0.05)$. Conclusion The incidence of CD in Sweden (1.6 cases per million) is in agreement with most previous reports. A higher incidence between 2005 and 2013 compared to 1987-2004 was noticed. Whether this reflects a truly increased incidence of the disease, or simply an increased awareness, earlier recognition, and earlier diagnosis can, however, not be answered. This study also illustrates the importance of validation of the diagnosis of $\mathrm{CD}$ in epidemiological research.
\end{abstract}

Keywords Cushing's syndrome $\cdot$ Epidemiology $\cdot$ Incidence $\cdot$ Validation

\section{Introduction}

Cushing's disease $(\mathrm{CD})$ is a rare disorder with an estimated annual incidence between 1.2 and 2.4 cases per million [1-7]. Studies on the incidence of CD are, however, few and usually limited by the small number of patients included $[1-4,6,7]$. Similarly, epidemiological studies on comorbidity and mortality are often based on small patient cohorts and/or short follow-up time [1, 2, 4, 5, 8-13]. The largest epidemiological study on mortality in patients with $\mathrm{CD}$

Electronic supplementary material The online version of this article (https://doi.org/10.1007/s11102-019-00951-1) contains supplementary material, which is available to authorized users.

Oskar Ragnarsson

oskar.ragnarsson@medic.gu.se

Extended author information available on the last page of the article published so far included 320 patients in remission. Patients from four countries were included and the median followup time was 11.8 years [14]. In a recent meta-analysis, data from eight studies were pooled, resulting in a total of 700 patients [15]. Thus, knowledge on epidemiology and outcome in Cushing's syndrome (CS), including CD, is still limited.

Since 1987, more than $99 \%$ of all diagnostic codes at hospital discharge are registered in the Swedish National Patient Register (Patient Register) [16]. The register holds a high quality with a positive predictive value (PPV) above 95\% for diagnoses such as myocardial infarction [17], rheumatoid arthritis [18], and hip fracture [19]. Whether this also applies for CD is unknown.

Thus, the aim of the present study was to validate the diagnosis in patients with presumed CD in Sweden and to calculate the annual incidence of the disease. 


\section{Methods}

This was a retrospective study where the medical records of patients with presumed CD identified in the Swedish Patient Register were reviewed to validate the diagnosis and to estimate the incidence of CD in Sweden between 1987 and 2013.

\section{Identification of patients}

During all hospital visits in Sweden, a diagnostic code for the main reason for the visit, as well as for all secondary diagnoses, are registered according to the International Classification of Diseases (ICD) system. In our study we used the following diagnostic codes to identify patients with $\mathrm{CD}$ in the Patient Register:

A. ICD-9 (between 1987 and 1996):

(a) CS (255A) and/or

(b) CS $(255 \mathrm{~A})+$ benign neoplasm of pituitary gland and craniopharyngeal duct (227D).

B. ICD-10 (between 1997 and 2013):

(c) CS (255A) and/or

(d) $\mathrm{CD}(\mathrm{E} 24.0)+$ benign pituitary adenoma (D35.2) and/or

(e) CS (E24.9) + benign pituitary adenoma (D35.2)

We recorded all occasions when one of these codes had been registered in connection with a hospital visit together with the unique social security number of the patient, date of the visit, and the name of the health care unit.

\section{Validation of the CD diagnosis}

A list of the patients identified was sent to the eight university hospitals in Sweden where the patients had received their diagnosis and/or had been treated. The medical records were reviewed, and the diagnosis validated through collection of clinical, biochemical, imaging, and histopathological data by either an endocrinologist experienced in diagnosing and treating CS or a resident in endocrinology under supervision of an experienced endocrinologist. A standardized case reporting form was used at all the clinics to capture information on date of diagnosis, treatment, remission status, presence and treatment of hypopituitarism, hypertension, diabetes mellitus, and osteoporosis (Online Appendix Fig. S1). When a diagnosis of CD was not confirmed, the correct diagnosis was provided.

The diagnosis of CD was based on collection of following information: (a) clinical features where symptoms and signs such as central obesity, hypertension, muscle weakness, fatigue, and menstrual irregularities/amenorrhea were considered to be typical for CD; (b) biochemical analyses including measurements of urinary free cortisol, plasma ACTH, midnight serum/salivary cortisol, dexamethasone suppressions tests, corticotropin-releasing hormone test, and metyrapone stimulation test; (c) visible pituitary tumor on magnetic resonance imaging; (d) results from inferior petrosal sinus sampling; and (e) histopathological diagnosis.

Thereafter, the patients were assigned to one of the following five groups: (a) confirmed CD; (b) other forms of CS (e.g. cortisol-producing adrenal adenoma, ectopic ACTH-producing tumors, cortisol-producing adrenocortical cancer); (c) CD diagnosis possible but not confirmed; (d) diagnoses related to CS (e.g., suspected CS that was ruled out after evaluation, drug-induced CS); and (e) diagnoses unrelated to $\mathrm{CS}$.

\section{Ethics}

The study was approved by the Regional Ethical Review Board in Gothenburg, Sweden (reference number 145/11; approved 25 April 2013) and by the National Board of Health and Welfare, Sweden.

\section{Statistical analysis}

Categorical variables are presented as number $(n)$ and percentages, and continuous variables as mean \pm SD or median [interquartile range (IQR); range]. For comparison of continuous variables between two groups, the unpaired t-test was used for normally distributed data and Mann-Whitney U-test for non-normally distributed data. For proportions, Pearson Chi square or Fisher's exact test were used. A two-sided $P$ value of $<0.05$ was considered statistically significant.

The annual incidence of CD was calculated by dividing the number of patients diagnosed with $\mathrm{CD}$ by the mean number of inhabitants in Sweden during each specific year and is presented as the number of cases per million together with 95\% confidence intervals (CIs). The mean annual incidence during the whole period (1987-2013) was calculated as well as the mean annual incidence during three 9-year periods (1987-1995, 1996-2004, and 2005-2013). Information on the number of individuals living in Sweden during the study period was collected from Statistics Sweden (http://www. scb.se/en).

Statistical analyses were performed with SPSS version 25.0 for Windows. 


\section{Results}

\section{Validation of the diagnosis}

In total, 1317 patients had received a diagnostic code for CS between 1987 and 2013 in the Patient Register in Sweden. Review of patient records verified the diagnosis of CD in 534 patients $(41 \%)$ whereas $610(46 \%)$ did not have CD (Table 1). In 41 patients (3\%) the diagnosis of CD was probable but could not be confirmed. Medical records for $132(10 \%)$ patients were missing. The majority of study patients with missing data $(112 ; 85 \%)$ had received the diagnostic code for CS before 1997 (ICD-9).

Table 1 Patients who had received a diagnostic code for (a) CS (255A), (b) CS (255A) + benign neoplasm of pituitary gland and craniopharyngeal duct (227D), (c) CD (E24.0), (d) CD (E24.0) + benign pituitary adenoma (D35.2), and/or (e) CS (E24.9) + benign pituitary adenoma (D35.2) in Sweden between 1987 and 2013

\begin{tabular}{lc}
\hline & No. of patients \\
& $(\%)(N=1317)$ \\
\hline CD & $534(41)$ \\
CD probable but not confirmed & $41(3)$ \\
Other causes of CS & $156(12)$ \\
Cortisol-producing adrenal adenoma & $86(7)$ \\
Ectopic ACTH-producing tumors & $52(4)$ \\
Cortisol-producing adrenal carcinoma & $17(1)$ \\
Primary pigmented nodular adrenocortical disease & $1(<1)$ \\
Diagnoses related to CS & $120(9)$ \\
Suspected CS, ruled out after evaluation & $86(7)$ \\
Drug-induced CS & $32(2)$ \\
Glucocorticoid receptor resistance & $2(<1)$ \\
Diagnoses, not related to CS & $334(25)$ \\
Non-functioning adrenal adenoma & $44(3)$ \\
Diabetes mellitus & $38(3)$ \\
Pituitary disease, not adenoma & $24(2)$ \\
Addison's disease & $14(1)$ \\
Craniopharyngioma & $12(1)$ \\
Non-functioning pituitary adenoma & $12(1)$ \\
Congenital adrenal hyperplasia & $9(1)$ \\
Acromegaly & $10(1)$ \\
Prolactinoma & $8(1)$ \\
Neuroendocrine tumor (carcinoid) & $8(1)$ \\
Aldosterone-producing adrenal adenoma & $7(1)$ \\
Other endocrine diagnoses & $26(2)$ \\
Other unrelated diagnoses & $122(9)$ \\
Medical records missing & $132(10)$ \\
\hline &
\end{tabular}

$A C T H$ adrenocorticotropic hormone, $C D$ Cushing's disease, $C S$ Cushing's syndrome
Of the 534 patients with confirmed CD, typical signs and symptoms were documented in the medical records of 469 (88\%) patients, $460(86 \%)$ had documented biochemical analyses supporting the diagnosis, $287(54 \%)$ had a visible pituitary adenoma on imaging, 176 (33\%) had performed an inferior petrosal sinus sampling, and a histopathological diagnosis was available in 215 patients (40\%).

Of 610 patients without $\mathrm{CD}, 156$ (12\% of the whole cohort) had endogenous CS of other causes, 86 (7\%) had a suspected CS that was eventually ruled out after clinical and biochemical evaluation, and $32(2 \%)$ had a drug-induced (iatrogenic) CS (Table 1). Three-hundred-and-thirty-four patients had diagnoses unrelated to CS (25\% of the whole cohort).

\section{Alternative search strategy}

The median (IQR; range) number of occasions that patients with confirmed $C D$ had received a diagnostic code was 11 (6-18;1-97) compared to $1(1-2 ; 1-20)$ in patients with diagnoses unrelated to CS $(P<0.001)$. Eight-hundred-andeight patients had received at least one of the predefined diagnostic codes on more than one occasion: 507 (63\%) patients with CD and 235 (29\%) without CD (Table 2). Of the total cohort of 1317 patients, $1022(78 \%)$ had received the diagnosis as the main reason for their visit: 497 (49\%) patients with CD and 419 (41\%) without CD. By including only patients with a diagnostic code for $\mathrm{CD}$ on more than one occasion and at least once as a main reason for their visit, 709 patients would have been identified: 479 (68\%) with $\mathrm{CD}$ and $181(26 \%)$ without CD.

Of the 731 patients who had received an ICD-10 code for $\mathrm{CD}, 511(70 \%)$ had been registered on at least two occasions: 397 (54\%) with CD and 99 (25\%) without CD (Table 2). By including only patients who had received an ICD-10 diagnostic code for CS on more than one occasion and at least once as the main reason for their visit, 485 patients would have been identified: 390 (80\%) patients with CD and 82 (17\%) without CD.

\section{Patients with confirmed CD}

Of 534 patients with confirmed CD, 410 (77\%) were women and 124 were men $(23 \%)$. The mean $( \pm \mathrm{SD})$ age at diagnosis was $43 \pm 16$ years (Fig. 1). Thirty-two (6\%) patients were younger than 18 years at the time of diagnosis: 17 (53\%) girls and 15 (47\%) boys. Median (IQR; range) follow-up time was $10(4-21 ; 0-55)$ years.

Information on treatment was available in 494 (93\%) of patients with confirmed $\mathrm{CD}$. The primary treatment modality was pituitary surgery in $381(77 \%)$ patients, radiation therapy in 57 (12\%) and bilateral adrenalectomy in $56(11 \%)$. 


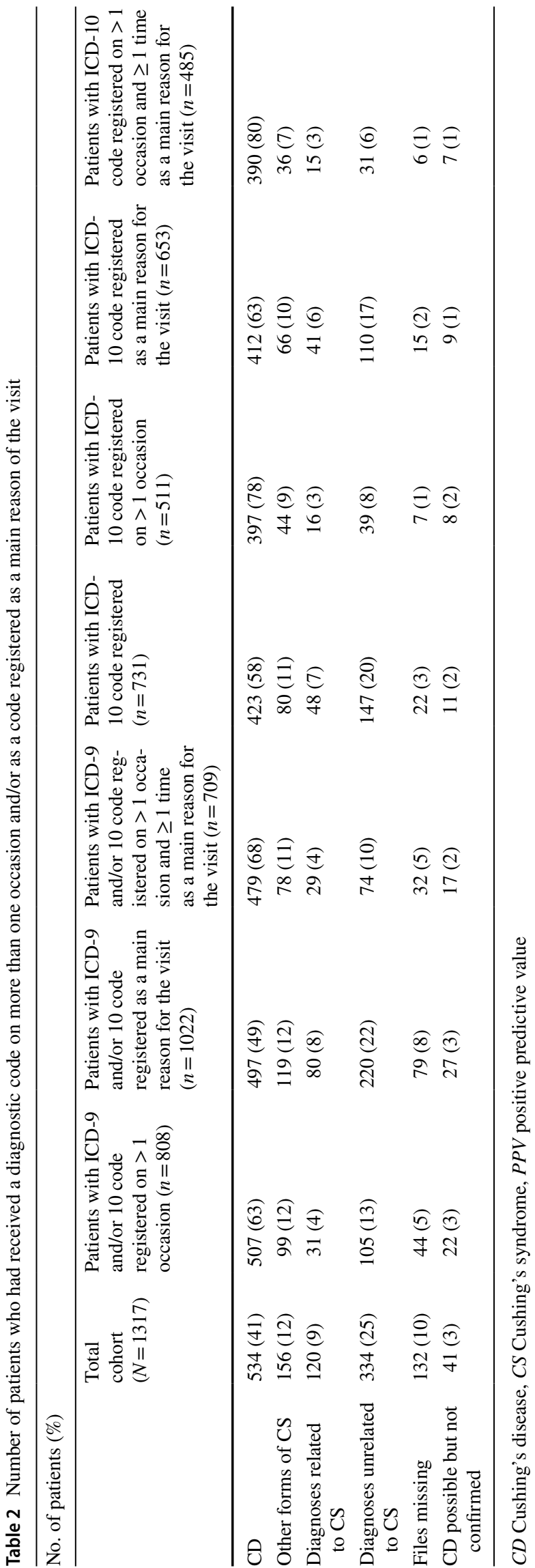

The primary treatment in 331 of 342 (97\%) patients, diagnosed with CD 1990 or later, was pituitary surgery.

\section{Annual incidence of CD}

Of 534 patients with confirmed CD, 144 were excluded from the incidence analysis as their diagnosis was made before 1987. In total, 390 patients were diagnosed with CD in Sweden between 1987 and 2013. The mean (95\% CI) annual incidence during the whole study period was 1.6 (1.4-1.8) cases per million (Fig. 2). The mean annual incidence was $1.5(1.1-1.8)$ cases per million between 1987 and 1995, $1.4(1.0-1.7)$ cases per million between 1996 and 2004, and $2.0(1.7-2.3)$ cases per million between 2005 and 2013. The mean annual incidence was higher during the last time period than during the first $(P=0.022)$ and the second $(P=0.009)$ time periods.

\section{Discussion}

This study illustrates the importance of validating diagnosis in patients with presumed CD from large health care registries such as national registries. Of 1317 patients identified in the Swedish Patient Register, approximately half had endogenous CS, of whom 534 had CD.

Although $\mathrm{CD}$ has been known as a clinical entity for more than 100 years, epidemiological studies evaluating incidence are surprisingly few and most often based on small numbers of patients ( $n=19-73$; Table 3$)$ [1-4, 6, 7]. The largest study published to date on incidence was based on 188 patients diagnosed with CD between 1960 and 2005 in New Zealand [5]. The incidence in these studies varies between 1.2 and 1.8 cases per million/year [1,3-6] with the exception of the study by Etxabe and Vazquez [2] who reported an incidence of 2.4 cases per million/year. Our result of 1.6 cases per million is therefore in agreement with most previous reports. In a recent study from the USA, an unexpectedly high incidence rate of 6.2-7.6 cases per million/year was reported [20]. That study was based on information from an insurance database where $\mathrm{CD}$ was defined as a CS diagnosis (as for ICD-9) plus the diagnosis of pituitary adenoma and/ or hypophysectomy. There may be several reasons for this surprisingly high incidence, but most importantly, the medical records of the patients were not reviewed. It is therefore likely that the incidence was overestimated as indicated in our study.

We noticed a higher mean incidence between 2005 and 2013 compared to 1987-2004. Whether this reflects a truly increased incidence of the disease or simply an increased awareness, earlier recognition, and earlier diagnosis cannot be answered. 
Fig. 1 Age distribution at first diagnosis in patients with confirmed CD in Sweden
Fig. 2 Annual incidence (cases per 1 million inhabitants per year) of CD in Sweden between 1987 and 2013

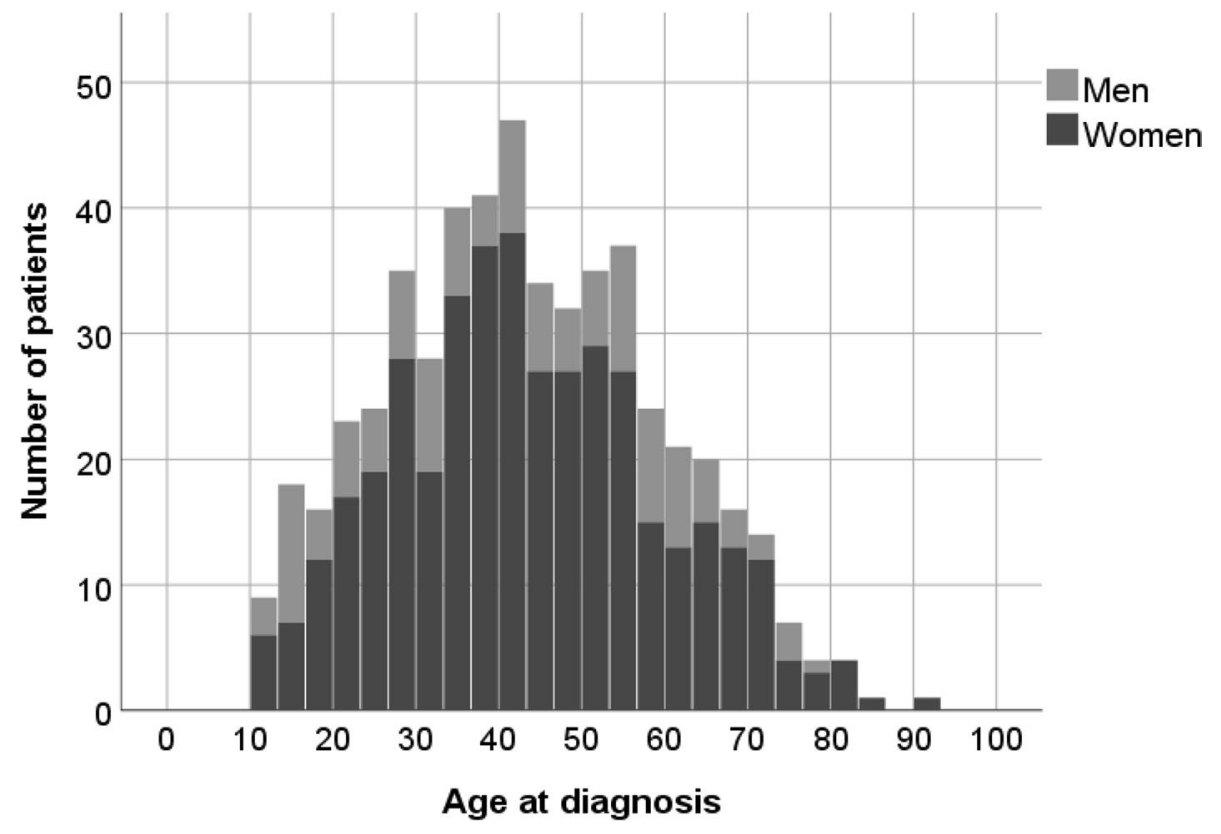

Between 1987 and 1996, discharge diagnoses in the Swedish National Register were coded according to the ICD-9 system, and thereafter according to ICD-10 criteria. In the ICD-9 criteria, only one code (255A) was available for CS. Thus, patients with all subtypes of the syndrome received the same diagnostic code irrespective of etiology. In the ICD-10 system, seven subtypes of CS were introduced including pituitary-dependent $\mathrm{CD}$. Although this was an important improvement compared to the ICD-9 system, several CS diagnoses, especially cortisol-producing adrenal adenomas, did not receive a specific code. Since ICD-10 has a specific code for $\mathrm{CD}$, we had expected that the reliability for the code would be much higher compared to ICD-9.
However, just more than half of the patients with a diagnostic code for CD according to ICD 10 actually had the disease and $20 \%$ had a diagnosis completely unrelated to CS.

Combined search criteria have previously been proposed to identify patients for epidemiological research of rare diseases [21]. In fact, we have used this strategy successfully in epidemiologic studies on patients with Addison's disease, craniopharyngioma, and non-functioning pituitary adenoma [22-24]. In the current study, we analyzed the influence of a combined search criteria on the accuracy of the diagnosis, i.e. by including only patients who had received the diagnosis more than once, only when the diagnosis was registered as a main cause of the visit, or a combination of both 
Table 3 Summary of previous studies analyzing the annual incidence rate of CD

\begin{tabular}{|c|c|c|c|c|c|}
\hline $\begin{array}{l}\text { Author (year of publication) } \\
\text { [reference] }\end{array}$ & Country & Period & No. of patients & $\begin{array}{l}\text { Incidence (per } \\
\text { million per } \\
\text { year) }\end{array}$ & Comments \\
\hline $\begin{array}{l}\text { Etxabe and Vazquez (1994) } \\
\text { [2] }\end{array}$ & Spain, Biscay province & 1975-1992 & 41 & 2.4 & \\
\hline Lindholm et al. (2001) [1] & Denmark, nationwide & $1985-1995$ & $73(99)$ & $1.2(1.7)$ & $\begin{array}{l}73 \text { patients with confirmed CD, } \\
\text { additionally } 26 \text { probably with } \\
\text { CD }\end{array}$ \\
\hline Raappana et al. (2010) [7] & Finland, northern & 1992-2007 & 19 & 1.7 & Medical records reviewed \\
\hline $\begin{array}{l}\text { Arnardottir and Sigurjonsdot- } \\
\text { tir (2011) [3] }\end{array}$ & Iceland, nationwide & $1955-2009$ & 19 & 1.5 & Medical records reviewed \\
\hline Clayton et al. (2011) [4] & UK, Stoke-on-Trent & $1958-2010$ & 60 & 1.5 & Medical records reviewed \\
\hline Bolland et al. (2011) [5] & New Zealand, nationwide & $1960-2005$ & 188 & 1.3 & $\begin{array}{l}\text { Medical records reviewed at } 4 \\
\text { main centers (>90\% of CS } \\
\text { patients in the country) }\end{array}$ \\
\hline Trjornstrand et al. (2014) [6] & $\begin{array}{l}\text { Sweden, Västra Götaland } \\
\text { County }\end{array}$ & 2001-2011 & 25 & 1.8 & $\begin{array}{l}\text { Patients identified in the Swed- } \\
\text { ish Pituitary Registry }\end{array}$ \\
\hline Broder et al. (2015) [20] & USA & 2009-2010 & 166 & $\begin{array}{l}7.6 \text { in } 2009 \\
6.2 \text { in } 2010\end{array}$ & $\begin{array}{l}\text { CD defined as the diagnosis } \\
\text { of (ICD-9) CS + pituitary } \\
\text { adenoma or hypophysectomy } \\
\text { identified in an insurance } \\
\text { database } \\
\text { Medical records not reviewed } \\
\text { Only patients } \leq 65 \text { years } \\
\text { No. of patients in the database } \\
\text { used as denominator }\end{array}$ \\
\hline Current study & Sweden, nationwide & $1987-2013$ & 534 & 1.6 & $\begin{array}{l}390 \text { patients included in the } \\
\text { incidence analysis }\end{array}$ \\
\hline
\end{tabular}

$C D$ Cushing's disease, $C S$ Cushing's syndrome

(Table 2). Unexpectedly, no combination resulted in acceptable accuracy for finding patients with $\mathrm{CD}$ : too many patients without CS were still identified and too many patients with true CS were not included. Similarly, by using a pituitary adenoma diagnosis in combination with CS (ICD-9) or CD (ICD-10), two-thirds of patients would have been missed in the ICD-9 system and almost half of the patients in the ICD-10 system.

The main strength of this study is the large number of patients where the diagnosis of $\mathrm{CD}$ was thoroughly evaluated. In fact, this is the largest study on incidence in patients with CD published so far. Another strength is the use of a national registry with almost $100 \%$ coverage of all patient visits in Sweden. There are, however, some limitations that need to be acknowledged. Medical records for $10 \%$ of the patients could not be retrieved despite vigorous efforts. Most of the files that were missing belonged to patients who had received the diagnosis more than 20 years previously. Also, the retrospective evaluation of the diagnosis of $\mathrm{CD}$ may have limitations. Although it can be considered a limitation that 41 patients had possible but unconfirmed $\mathrm{CD}$, and were therefore not included in the incidence analysis, it can also be considered a strength that only patients with a confirmed diagnosis were included.
In conclusion, this nationwide study demonstrates the importance of validation of the diagnosis when using registries for epidemiological research in rare diseases such as CD. A correct diagnosis of $\mathrm{CD}$ was verified in less than half of the patients. Thus, the results from previous and future epidemiological studies using ICD coding for inclusion of patients with $\mathrm{CD}$, as well as other rare and complex diseases, should be questioned.

Funding The Gothenburg Society of Medicine.

Open Access This article is distributed under the terms of the Creative Commons Attribution 4.0 International License (http://creativeco mmons.org/licenses/by/4.0/), which permits unrestricted use, distribution, and reproduction in any medium, provided you give appropriate credit to the original author(s) and the source, provide a link to the Creative Commons license, and indicate if changes were made.

\section{References}

1. Lindholm J, Juul S, Jørgensen JO, Astrup J, Bjerre P, Feldt-Rasmussen U et al (2001) Incidence and late prognosis of Cushing's 
syndrome: a population-based study. J Clin Endocrinol Metab 86(1):117-123

2. Etxabe J, Vazquez JA (1994) Morbidity and mortality in Cushing's disease: an epidemiological approach. Clin Endocrinol (Oxf) 40(4):479-484

3. Arnardóttir S, Sigurjonsdóttir HA (2011) The incidence and prevalence of Cushing's disease may be higher than previously thought: results from a retrospective study in Iceland 1955 through 2009. Clin Endocrinol (Oxf) 74(6):792-793. https://doi.org/10.11 11/j.1365-2265.2010.03961.x

4. Clayton RN, Raskauskiene D, Reulen RC, Jones PW (2011) Mortality and morbidity in Cushing's disease over 50 years in Stoke-on-Trent, UK: audit and meta-analysis of literature. J Clin Endocrinol Metab 96(3):632-642. https://doi.org/10.1210/ jc. 2010-1942

5. Bolland MJ, Holdaway IM, Berkeley JE, Lim S, Dransfield WJ, Conaglen JV et al (2011) Mortality and morbidity in Cushing's syndrome in New Zealand. Clin Endocrinol (Oxf) 75(4):436-442. https://doi.org/10.1111/j.1365-2265.2011.04124.x

6. Tjörnstrand A, Gunnarsson K, Evert M, Holmberg E, Ragnarsson O, Rosén $\mathrm{T}$ et al (2014) The incidence rate of pituitary adenomas in western Sweden for the period 2001-2011. Eur J Endocrinol 171(4):519-526. https://doi.org/10.1530/EJE-14-0144

7. Raappana A, Koivukangas J, Ebeling T, Pirilä T (2010) Incidence of pituitary adenomas in Northern Finland in 1992-2007. J Clin Endocrinol Metab 95(9):4268-4275. https://doi.org/10.1210/ jc.2010-0537

8. Pikkarainen L, Sane T, Reunanen A (1999) The survival and wellbeing of patients treated for Cushing's syndrome. J Intern Med 245(5):463-468

9. Swearingen B, Biller BM, Barker FG, Katznelson L, Grinspoon S, Klibanski A et al (1999) Long-term mortality after transsphenoidal surgery for Cushing disease. Ann Intern Med 130(10):821-824

10. Hammer GD, Tyrrell JB, Lamborn KR, Applebury CB, Hannegan ET, Bell S et al (2004) Transsphenoidal microsurgery for Cushing's disease: initial outcome and long-term results. J Clin Endocrinol Metab 89(12):6348-6357. https://doi.org/10.1210/ jc. 2003-032180

11. Dekkers OM, Biermasz NR, Pereira AM, Roelfsema F, van Aken MO, Voormolen JH et al (2007) Mortality in patients treated for Cushing's disease is increased, compared with patients treated for nonfunctioning pituitary macroadenoma. J Clin Endocrinol Metab 92(3):976-981. https://doi.org/10.1210/jc.2006-2112

12. Hassan-Smith ZK, Sherlock M, Reulen RC, Arlt W, Ayuk J, Toogood AA et al (2012) Outcome of Cushing's disease following transsphenoidal surgery in a single center over 20 years. J Clin Endocrinol Metab 97(4):1194-1201. https://doi.org/10.1210/ jc.2011-2957

13. Ntali G, Asimakopoulou A, Siamatras T, Komninos J, Vassiliadi D, Tzanela M et al (2013) Mortality in Cushing's syndrome: systematic analysis of a large series with prolonged follow-up. Eur J Endocrinol 169(5):715-723. https://doi.org/10.1530/EJE-13-0569
14. Clayton RN, Jones PW, Reulen RC, Stewart PM, Hassan-Smith ZK, Ntali G et al (2016) Mortality in patients with Cushing's disease more than 10 years after remission: a multicentre, multinational, retrospective cohort study. Lancet Diabetes Endocrinol 4(7):569-576. https://doi.org/10.1016/S2213-8587(16)30005-5

15. van Haalen FM, Broersen LH, Jorgensen JO, Pereira AM, Dekkers OM (2015) Management of endocrine disease. Mortality remains increased in Cushing's disease despite biochemical remission: a systematic review and meta-analysis. Eur J Endocrinol 172(4):R143-R149. https://doi.org/10.1530/EJE-14-0556

16. Ludvigsson JF, Andersson E, Ekbom A, Feychting M, Kim JL, Reuterwall C et al (2011) External review and validation of the Swedish national inpatient register. BMC Public Health 11:450. https://doi.org/10.1186/1471-2458-11-450

17. Linnersjö A, Hammar N, Gustavsson A, Reuterwall C (2000) Recent time trends in acute myocardial infarction in Stockholm, Sweden. Int J Cardiol 76(1):17-21

18. Turesson C, Jacobsson L, Bergström U (1999) Extra-articular rheumatoid arthritis: prevalence and mortality. Rheumatology 38(7):668-674

19. Michaëlsson K, Baron JA, Farahmand BY, Johnell O, Magnusson C, Persson PG et al (1998) Hormone replacement therapy and risk of hip fracture: population based case-control study. The Swed Hip Fract Study Group BMJ 316(7148):1858-1863

20. Broder MS, Neary MP, Chang E, Cherepanov D, Ludlam WH (2015) Incidence of Cushing's syndrome and Cushing's disease in commercially-insured patients $<65$ years old in the United States. Pituitary 18(3):283-289. https://doi.org/10.1007/s1110 2-014-0569-6

21. Nielsen EH, Lindholm J, Laurberg P (2011) Use of combined search criteria improved validity of rare disease (craniopharyngioma) diagnosis in a national registry. J Clin Epidemiol 64(10):1118-1126. https://doi.org/10.1016/j.jclinepi.2010.12.016

22. Olsson DS, Nilsson AG, Bryngelsson IL, Trimpou P, Johannsson G, Andersson E (2015) Excess mortality in women and young adults with nonfunctioning pituitary adenoma: a Swedish nationwide study. J Clin Endocrinol Metab 100(7):2651-2658. https:// doi.org/10.1210/jc.2015-1475

23. Olsson DS, Andersson E, Bryngelsson IL, Nilsson AG, Johannsson $\mathrm{G}$ (2015) Excess mortality and morbidity in patients with craniopharyngioma, especially in patients with childhood onset: a population-based study in Sweden. J Clin Endocrinol Metab 100(2):467-474. https://doi.org/10.1210/jc.2014-3525

24. Bergthorsdottir R, Leonsson-Zachrisson M, Odén A, Johannsson G (2006) Premature mortality in patients with Addison's disease: a population-based study. J Clin Endocrinol Metab 91(12):4849_ 4853. https://doi.org/10.1210/jc.2006-0076

Publisher's Note Springer Nature remains neutral with regard to jurisdictional claims in published maps and institutional affiliations. 


\section{Affiliations}

Oskar Ragnarsson ${ }^{1}$ (D) Daniel S. Olsson ${ }^{1} \cdot$ Dimitrios Chantzichristos $^{1} \cdot$ Eleni Papakokkinou ${ }^{1} \cdot$ Per Dahlqvist $^{2}$. Elin Segerstedt ${ }^{2} \cdot$ Tommy Olsson $^{2} \cdot$ Maria Petersson $^{3,4} \cdot$ Katarina Berinder $^{3,4} \cdot$ Sophie Bensing ${ }^{3,4}$.

Charlotte Höybye $^{3,4}$ • Britt Edén Engström ${ }^{5}$. Pia Burman ${ }^{6,7}$. Lorenza Bonelli, ${ }^{6,7}$. Cecilia Follin ${ }^{8}$. David Petranek ${ }^{8}$. Eva Marie Erfurth ${ }^{8}$. Jeanette Wahlberg ${ }^{9} \cdot$ Bertil Ekman $^{9} \cdot$ Anna-Karin Åkerman $^{10}$. Erik Schwarcz ${ }^{10}$. Ing-Liss Bryngelsson ${ }^{11}$. Gudmundur Johannsson ${ }^{1}$

1 Department of Internal Medicine and Clinical Nutrition, Institute of Medicine at Sahlgrenska Academy, University of Gothenburg, and The Department of Endocrinology, Sahlgrenska University Hospital, Gröna Stråket 8,

41345 Gothenburg, Sweden

2 Department of Medicine, Umeå University, 90187 Umeå, Sweden

3 Patient Area Endocrinology and Nephrology, Inflammation and Infection Theme, Karolinska University Hospital, 17176 Solna, Sweden

4 Department of Molecular Medicine and Surgery, Karolinska Institutet, 17177 Stockholm, Sweden

5 Department of Medical Sciences, Endocrinology, Diabetes and Metabolism, Uppsala University Hospital, 75185 Uppsala, Sweden
6 Department of Endocrinology, Skåne University Hospital, 21428 Malmö, Sweden

7 University of Lund, 22350 Lund, Sweden

8 Department of Endocrinology, Skåne University Hospital, 22242 Lund, Sweden

9 Department of Endocrinology, Department of Medical and Health Sciences, Linköping University, 58183 Linköping, Sweden

10 Department of Internal Medicine, School of Medical Sciences, Örebro University, 70281 Örebro, Sweden

11 Department of Occupational and Environmental Medicine, Örebro University Hospital, 70281 Örebro, Sweden 